\title{
Predictions of Energy Intake and Energy Allowance of Patients with Duchenne Muscular Dystrophy and Their Validity
}

\author{
Kazuko OKada, Sachinobu Manabe, Sadaichi SaKamoto, \\ Masaharu OHNAKA, and Yoshiaki NiIYAMA \\ Department of Nutrition, School of Medicine, The University of Tokushima, \\ Tokushima 770, Japan
}

(Received September 12, 1991)

\begin{abstract}
Summary Patients with Duchenne muscular dystrophy are so malnourished that energy supplementation is crucial. Their degree of energy deficiency was assessed as difference between their energy intake and their energy allowance, which were deduced from easily measured parameters. A significant, negative relationship was found between the basal metabolic rate $(\mathrm{BMR})(Y, \%, \mathrm{BMR} /$ standard $\mathrm{BMR})$ and body weight $(X, \%$, body weight/standard body weight) in the patients, from which the formula for the BMR was deduced to be $Y=-1.116 X+174.5(n=202, r=-0.72$, $\mathrm{p}<0.001)$. Thus, it is possible to estimate the energy allowance for individual patients by a factorial procedure from the presumed BMR and a factor for physical activity. In addition, their energy intake was calculated from a constant protein-energy \% (14.6\%) in their diet and nitrogen intake which was deduced from a significant positive correlation between their nitrogen intake $(Y, \mathrm{mg} / \mathrm{kg} /$ day $)$ and their nitrogen excretion in $24 \mathrm{~h}$ urine samples $(X, \mathrm{mg} / \mathrm{kg} / \mathrm{day})$. This correlation conformed to the equation $Y=1.053 X+32.4(n=267, r=+0.76, p<0.001)$. The validities of the above predictions for energy intake and allowance were examined by plotting the degree of energy deficiency (\% ratio of presumed intake/ presumed allowance) against the concentrations of retinol binding protein, prealbumin and transferrin in the serum, because rapid turnover proteins are sensitive to energy deficiency. Significant positive correlations were obtained with both variables, suggesting that these predictions were valid.
\end{abstract}

Key Words progressive muscular dystrophy, predicted energy intake and allowance, intake $\mathrm{N}$ and urinary $\mathrm{N}$, protein-energy ratio, rapid turnover proteins 
Previously we reported that patients with Duchenne muscular dystrophy (DMD) are underweight and that their low body weights are due to increased energy expenditure and protein degradation, i.e., to enhanced needs, not to decreased food intake (1). Supplementation with protein and energy, especially the latter, may prevent or reverse their body weight loss and so prolong their life span. Appropriate supplementations of protein and energy for individual patients depend on the degree of deficit represented by the differences between the intake and allowance. However, procedures to determine the dietary intake and allowance for individuals are too complicated to be feasible. Thus, we tried to deduce the protein and energy intakes from the urinary nitrogen excretion and dietary protein-energy (PE)\% and to estimate the energy allowance using values for the basal metabolic rate (BMR) predicted from the inverse relationship between the body weight and BMR reported previously (1). To confirm the validity of these predictions, we examined the relationship of dietary deficit with the serum concentration of some rapid turnover proteins.

\section{EXPERIMENTAL}

The subjects examined and experimental procedures used were described in detail in our previous paper (1). Briefly, a total of 310 DMD patients, aged 11 to 29, were included in this study. Protein and energy intakes were estimated from data on the weights of foods consumed using a food composition table and then the dietary protein-energy (PE) \% was calculated.

The basal metabolic rate was measured by indirect calorimetry. The apparent nitrogen balance was obtained by subtracting excreted $\mathrm{N}$ (determined in $24 \mathrm{~h}$ urine and fecal samples) from the ingested $\mathrm{N}$ (determined as the difference between $\mathrm{N}$ in served foods and uneaten foods).

The adequacy of energy intake was assessed by comparing the intake with the allowance (I/A ratio). The energy allowance was calculated by a routine factorial procedure using the measured BMR and a factor for physical activity of $0.3(2)$.

The concentrations of the rapid turnover proteins, prealbumin, retinol binding protein (RBP) and transferrin, in the sera of 19 DMD patients were determined by a radial immunodiffusion method (3).

\section{RESULTS}

\section{Prediction of the BMR for individual patients from their body weight loss}

Previously we showed that, compared with control values, mean body weight decreased and the mean $\mathrm{BMR}(\mathrm{kcal} / \mathrm{kg})$ increased in the respective age groups of DMD patients with age and progression of the disease (1). As increase in energy expenditure results in greater body weight loss, it seemed appropriate to relate the increase in the BMR with that of body weight loss. Thus, to obtain a formula for predicting the BMR directly from the body weight loss, the extent of BMR increase 


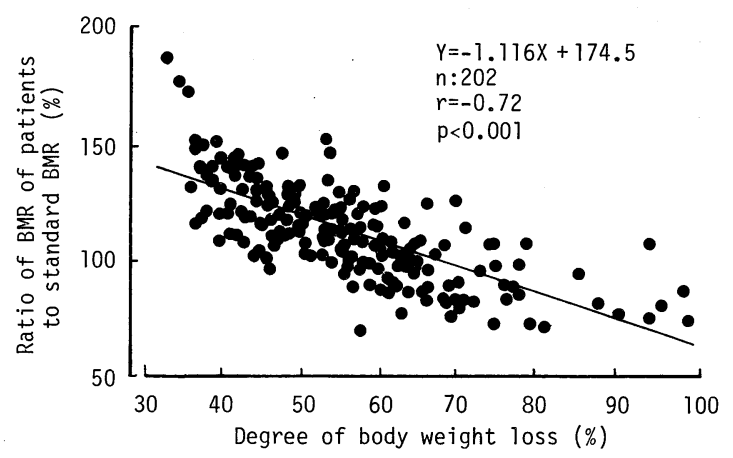

Fig. 1. Correlation between body weight and BMR in patients with Duchenne muscular dystrophy. Regression equation and correlation coefficient obtained by adopting linear, quadratic and hyperbolic functions were as follows: linear: $Y=$ $-1.116 X+174.5, r=-0.72(p<0.001)$; quadratic: $Y=0.18 X^{2}-3.33 X+238.4$, $r=0.75(p<0.001)$; hyperbolic: $Y=3,612.05(1 / X)+44.0, r=0.75(p<0.001)$. There were no statistical differences among correlation coefficients obtained by three function models. Thus, we used linear regression equation, because of its simplicity.

( $Y, \%$, measured $\mathrm{BMR} /$ standard $\mathrm{BMR}$ ) was plotted against the degree of body weight loss $(X, \%, \mathrm{BW} /$ standard $\mathrm{BW})$, using values for 202 patients. Figure 1 shows the negative correlation between these two variables, conforming to the equation $Y=-1.116 X+174.5(n=202, r=-0.72, p<0.001)$. From this equation and standard values for the BMR and body weight for each age, we can predict the BMR for individuals and then can estimate their energy allowance.

\section{Prediction of energy intake from urinary nitrogen excretion}

The dietary PE\% is known to be relatively constant (4). If this is also true for the patients and the protein intake is known, the energy intake of individuals can be calculated. Our patients ate some of the food in served meals according to their preference and left some uneaten food, so we first examined the constancy of PE\% of ingested foods by plotting energy intake $(X, \mathrm{kcal} / \mathrm{day})$ against PE\% $(Y, \%)$. As shown in Fig. 2, there was no significant relation between the two and the regression equation was $Y=-0.00077 X+15.49(n=185, r=-0.12$, ns $)$, indicating that $\mathrm{PE} \%$ is fairly constant. In Fig. 2, the energy intakes and corresponding PE\% values ranged from 636 to $1,745 \mathrm{kcal} /$ day and 15.0 to $14.2 \%$, respectively. The mean $\mathrm{PE} \%$ for 185 patients was $14.6 \pm 1.5 \%$.

Next, a formula for predicting protein intake was derived from the significant relation between nitrogen intake $(Y, \mathrm{mg} / \mathrm{kg} / \mathrm{day})$ and urinary nitrogen $(X, \mathrm{mg} / \mathrm{kg} /$ day) shown in Fig. 3. The equation for the regression line was $Y=1.053 X+32.4$ $(n=267, r=+0.76, p<0.001)$. These values included those for considerable numbers of patients who were growing and accordingly retained more nitrogen than 


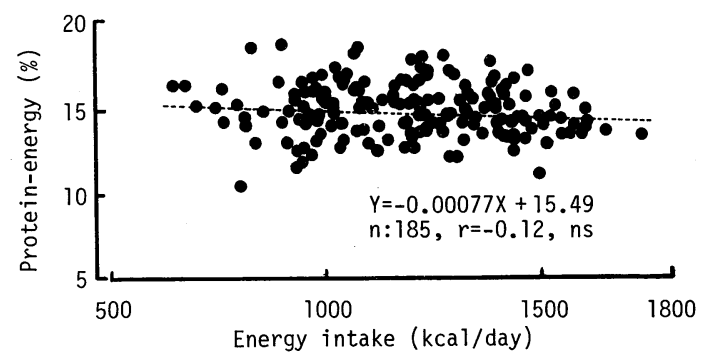

Fig. 2. Constancy of protein-energy of diets consumed by patients.

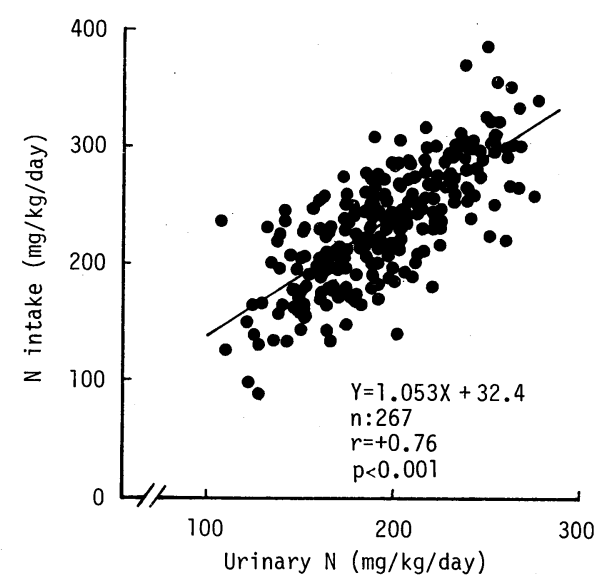

Fig. 3. Correlation between urinary nitrogen excretion and nitrogen intake in patients with Duchenne muscular dystrophy.

adult patients. However, we concluded that data for all the patients aged 11 to 29 years should be included, because their growth differences were small, the mean body weights of young and adult patients being about 26 and $30 \mathrm{~kg}$, respectively.

Urinary nitrogen excretion, determined on $24 \mathrm{~h}$ urine samples, is easier to measure than dietary nitrogen intake, and thus is a more practical method for predicting protein intake. Namely, energy intake of individuals can be estimated from their protein intakes deduced from their $24 \mathrm{~h}$ urinary nitrogen excretions, assuming a constant $\mathrm{PE} \%$ value.

Relation of adequacy of energy intake to the serum levels of rapid turnover proteins in DMD patients

To check the validity of predictions for energy intake and allowance, we examined the relationships of the degrees of dietary deficiency with the serum concentrations of RBP, prealbumin and transferrin in DMD patients, because transport proteins with rapid turnover are sensitive to dietary deficiency (5). Table 
Table 1. Dietary adequacy in DMD patients, judged from changes in serum levels of rapid turnover proteins.

\begin{tabular}{llcccc}
\hline Age & $(\mathrm{yr})$ & $12-13$ & $14-17$ & $18-27$ & $\begin{array}{c}\text { Control } \\
\text { No. of subjects }\end{array}$ \\
Body weight $(\mathrm{BW})$ & $(\mathrm{kg})$ & $36.5 \pm 11.5^{1}$ & $35.3 \pm 9.7$ & $33.5 \pm 7.8$ & $(14)$ \\
Decrease of $\mathrm{BW}$ & $(\%)$ & 81.6 & 58.8 & 53.4 & \\
Urinary N & $(\mathrm{g} / \mathrm{d})$ & $5.07 \pm 1.15$ & $4.93 \pm 0.92$ & $5.21 \pm 1.21$ & \\
Protein intake predicted & $(\mathrm{g} / \mathrm{d})$ & $40.7 \pm 9.6$ & $39.6 \pm 7.8$ & $41.1 \pm 8.9$ & \\
Energy intake predicted & $(\mathrm{kcal} / \mathrm{d})$ & $1,116 \pm 264$ & $1,085 \pm 213$ & $1,125 \pm 244$ & \\
BMR predicted & $(\mathrm{kcal} / \mathrm{d})$ & $896 \pm 60$ & $984 \pm 59$ & $919 \pm 118$ & \\
Energy allowance & $(\mathrm{kcal} / \mathrm{d})$ & $1,294 \pm 87$ & $1,422 \pm 86$ & $1,328 \pm 171$ & \\
Adequacy of energy intake & $(\%)$ & $87 \pm 25$ & $76 \pm 12$ & $85 \pm 16$ & \\
$\quad($ Intake/allowance) & & & & & \\
\hline $\begin{array}{l}\text { Retinol binding protein } \\
\text { Prealbumin }\end{array}$ & $(\mathrm{mg} / 100 \mathrm{ml})$ & $3.04 \pm 0.67^{\mathrm{b}}$ & $2.86 \pm 0.56^{\mathrm{a}}$ & $3.12 \pm 0.65^{\mathrm{a}}$ & $4.47 \pm 0.75$ \\
Transferrin & $(\mathrm{mg} / 100 \mathrm{ml})$ & $25.3 \pm 6.9^{\mathrm{b}}$ & $22.9 \pm 2.9^{\mathrm{a}}$ & $25.5 \pm 5.5^{\mathrm{a}}$ & $34.8 \pm 4.7$ \\
\hline
\end{tabular}

${ }^{1}$ Mean \pm SD. ${ }^{a}$ and ${ }^{b}$ : Significantly different from control value at levels of 0.1 and $1 \%$, respectively. The statistical significance was assessed by Student's $t$ test.

1 shows the relationships in three age groups of the adequacy of energy intake, assessed from the ratio of the predicted energy intake to the predicted energy allowance with the serum concentrations of these proteins. The body weights of young, adolescent and young adult patients (12 to 13,14 to 17 and over 18 years, respectively) as percentages of those of the respective age-matched controls were 82,59 and $53 \%$, respectively.

The intake and allowance of energy ( $\mathrm{kcal} / \mathrm{day}$ ) estimated using the above prediction were, respectively, 1,116 and 1,294 for the young group, 1,085 and 1,422 for the adolescent group and 1,125 and 1,328 for the young adult group. From these values the adequacies of energy intake were calculated to be 87,76 and $85 \%$, respectively.

The serum concentrations of all the rapid turnover proteins except transferrin were significantly lower in the patients than in healthy controls. Moreover, their concentrations were lowest in the adolescent group of patients who were the most deficient in energy. These findings suggest that the decreased concentrations of RBP and prealbumin in the serum of the patients resulted from inadequate energy intake. Thus, the relationships between the degree of energy deficiency and the serum concentrations of RBP and prealbumin were examined further. Plots of the adequacy of energy intake $(X, \%)$ against the concentration $(Y, \mathrm{mg} / 100 \mathrm{ml})$ of RBP or prealbumin showed significant rectilinear relationships conforming to the following equations: $Y=0.0263 X+0.839(n=19, r=0.71, p<0.001)$ for RBP and $Y=0.228 X+5.72(n=19, r=0.76, p<0.001)$ for prealbumin. As the concentrations of rapid turnover proteins are sensitive to protein and/or energy deficiency, these results indicate that our predictions for energy intake and energy allowance 
are valid. A significant correlation was also found between serum transferrin and energy sufficiency, using data from 19 patients $(Y=2.146 X+118.53, r=0.68, p<$ $0.01)$. However, further studies are necessary on why the mean serum transferrin concentration in the patients tended to be higher than that in healthy controls whose energy intake is probably adequate (Table 1 ).

\section{DISCUSSION}

The underweight of DMD patients is caused by energy deficiency resulting from hypermetabolism (1). Thus, to prolong the life span of these patients it is important to improve their nutritional status by supplying an appropriate amount of energy equal to, or more than the difference between their allowance and intake. However, measurements of the dietary intake and the BMR for estimation of the allowance involve complicated procedures. Therefore, in this work, based on anthropometric and metabolic data on 310 patients, we tried to obtain formulae for predicting the BMR from the degree of body weight loss and the energy intake, deduced from the urinary nitrogen excretion in $24 \mathrm{~h}$, assuming a constant PE\%. We also examined the validities of these predictions from the relationships between the degree of energy deficiency and the changes in serum concentrations of rapid turnover proteins.

With progress of the disease, the degrees of decrease in body weight and increase in the BMR relative to control values increase, and from the significant relationship between the two, we were able to predict the BMR from the reduction in body weight. A similar relationship was observed by Usutani et al. in 19 DMD patients (6). The mechanism of hypermetabolism in advanced DMD is unknown, but it seems reasonable to relate the two variables, because an increased BMR may result in body weight loss if the energy supply is not adequate. We were thus able to estimate the energy allowance for individual patients from the predicted BMR. For more exact determination of the BMR, it is desirable to use the standard body weight for height instead of the standard body weight in calculation of the degree of reduction in body weight. However, in most cases measurement of height was not possible, because the patients were deformed or could not stand.

For determination of the energy intake of individual patients, the assumptions that urinary nitrogen excretion increases with increase in nitrogen intake (7) and that the $\mathrm{PE} \%$ in the diet is nearly constant (4) were reexamined. A highly significant relationship between the intake and urinary excretion of nitrogen was demonstrated, allowing deduction of the nitrogen intake. From this deduced protein intake $(\mathrm{N} \times 6.25)$ and the constant $\mathrm{PE} \%$ value of $14.6 \%$ (Fig. 2), we estimated the energy intake of individuals. Collection of $24 \mathrm{~h}$ urine samples and analysis of urinary nitrogen by the Kjeldahl method are rather troublesome procedures, but are simpler than obtaining weighed dietary records.

The validity of the above predictions was shown indirectly by demonstrating significant positive correlations between the serum concentrations of rapid turnover 
proteins and the degrees of energy deficiency, because the levels of these proteins are known to be sensitive to energy deficiency $(5,8)$.

The relationships of the serum concentrations of rapid turnover proteins to the degree of protein deficiency were also examined (data not shown), but no significant correlations were found. This was mainly because the protein allowances were estimated to meet the needs of nearly all the patients (9) and, therefore, the degrees of protein deficiency (protein intake/protein allowance) were not exact like those of energy deficiency.

In this work, by use of relatively easily measurable parameters, such as the body weight and nitrogen excretion in $24 \mathrm{~h}$ urine samples, we could estimate the energy intake and allowance for individual patients, and determine their degrees of energy deficiency. Studies on the effects of energy supplementation on physical and physiological parameters of the patients are now in progress.

We thank Dr. Yutaka Matsuka, and Mmes. Satsuki Nii and Ikuyo Fujiwara of the National Sanatorium Tokushima Hospital for their cooperation. We are also grateful to Dr. Hisashi Kimura, Hirosaki University School of Medicine, for his continuous support. This work was supported in part by a grant (4-A) from the National Center of Neurology and Psychiatry (NCNP) of the Ministry of Health and Welfare, Japan.

\section{REFERENCES}

1) Okada, K., Manabe, S., Sakamoto, S., Ohnaka, M., and Niiyama, Y. (1992): Protein and energy metabolism in patients with progressive muscular dystrophy. J. Nutr. Sci. Vitaminol., 38, 141-154.

2) Kimura, H. (1975): Nutritional status of patients with progressive muscular dystrophy. Eiyo to Shokuryo (J. Jpn. Soc. Nutr. Food Sci.), 28, 377-382.

3) Mancini, G., Carbonara, A. O., and Heremans, J. F. (1965): Immunological quantitation of antigens by single radial immunodiffusion. Immunochemistry, 2, 235-254.

4) Joint of a FAO/WHO ad hoc Expert Committee (1973): Energy and Protein Requirement, WHO Tech. Rept. Ser., No. 522, pp. 21-22, Geneva.

5) Shetty, P. S., Watrasiewicz, K. E., Jung, R. T., and James, W. P. T. (1979): Rapid-turnover transport proteins: an index of subclinical protein energy malnutrition. Lancet, 2, 230-232.

6) Usutani, S., Nishiyama, K., Kida, K., Yamauchi, N., Kariya, K., Akimoto, Y., and Moriyama, A. (1984): Studies on energy requirement of patients with progressive muscular dystrophy. On the basal metabolism of PMD patients. Eiyogakuzasshi (Jpn. .J. Nutr. ), 42, 247-254.

7) Folin, O. (1905): A theory of protein metabolism. Am. J. Physiol., 13, 117-138.

8) Golden, M. H. N. (1982): Transport proteins as indices of protein status. Am. J. Clin. Nutr., 35, 1159-1165.

9) Subcommittee on the tenth edition of the RDAs, Food and Nutrition Board, Commission on Life Sciences, National Research Council (1989): Protein and amino acids, in Recommended Dietary Allowances, 10th ed., National Academy Press, Washington, D. C., pp. 58-59. 